\title{
Effect of Mixing Modes on Chemiluminescent Detection of Epinephrine with Lucigenin by an FIA System Fabricated on a Microchip
}

\author{
Tamio Kamidate, ${ }^{\dagger}$ Tomoyuki KaIDE, Hirofumi TAni, Eiji Makino, and Takayuki ShIBata
}

Graduate School of Engineering, Hokkaido University, Sapporo 060-8628, Japan

\begin{abstract}
The chemiluminescent (CL) detection of epinephrine (EP) with lucigenin (Luc) was performed using a micro flow cell fabricated on a silicon chip. A solution of EP was injected into the Luc carrier stream. The Luc solution containing EP and an alkaline solution were successively poured into the flow cell by a pressure-driven flow system. Two types of flow cells were fabricated for estimating the effect of the mixing modes in the flow cells on the intensity of light emission. In flow cell 1, two streams entered through separate inlet ports and merged to flow adjacently. In flow cell 2, a Luc solution containing EP was split up to 36 partial flows by passage through the nozzles, and was injected into the alkaline solution. The intensity of light emission in flow cell 2 increased markedly compared to that in flow cell 1 . The detection limit of $8.0 \times 10^{-7} \mathrm{M}$ for $\mathrm{EP}$ in flow cell 2 was a factor of six-times better than that in flow cell 1 . The improvement in the sensitivity for EP could be explained in terms of the distortion of laminar flow in flow cell 2.
\end{abstract}

(Received March 22, 2001; Accepted June 26, 2001)

Flow injection analysis (FIA) is widely used for the determination of trace analytes, such as metal ions and biological compounds, in view of its rapidity, precision, and ability to handle small sample volumes. ${ }^{1}$ Recently, micro FIA systems have been developed by microfabrication techniques, such as photolithography and anisotropic etching. Micro channels on a quartz glass chip were fabricated as a component in an integrated FIA system, in which the formation of the $\mathrm{Fe}(\mathrm{II})$ - o-phenanthroline complex was measured by a thermallens microscope. ${ }^{2}$ A microfabricated flow chamber was also developed for fluorescence-based chemistries and stopped-flow injection cytometry. ${ }^{3}$ In those micro FIA systems, the laserinduced optical method was used for the detection of an analyte passed through the channels, since a laser is suitable for being focused on the fluid in the channel.

A chemiluminescent (CL) method is being focused on its highly sensitivity and wide dynamic range. In addition, the instrumentation used in the CL method is relatively simpler compared to that in the laser-induced optical method, since a light source is not required in CL detection. Recently, the CL method has been applied to detection in microchip capillary electrophoresis. ${ }^{4,5} \mathrm{Wu}$ et al. applied the luminol and peroxyoxalate $\mathrm{CL}$ methods to the detection of $\mathrm{H}_{2} \mathrm{O}_{2}$ in the integrated FIA system with gravity as a driving force. ${ }^{6}$

In the FIA system, the reaction for detection is preferred to be complete within the residence time of the reactants in the flow cell. However, a fluid in a microfabricated channel is known to flow with laminar flow at a low flow rate. ${ }^{7}$ There is no convective mixing across two fluids with laminar flow, thus resulting in a decrease in the yield of the reaction due to insufficient mixing. In order to overcome these problems, micromixing devices have been developed based on distributive mixing. ${ }^{8,9}$ The fluid streams were split up into smaller segments by passage through micromixing devices for reducing the

$\doteqdot$ To whom correspondence should be addressed. diffusion length and mixing time of the reactants. The microstructure for efficient mixing has been applied to the luminol CL detection of $\mathrm{Cr}$ (III) in the continuous flow-injection mode. ${ }^{10}$

In this study, we fabricated two types of micro-flow cells with different mixing modes. The CL reaction of epinephrine (EP) with lucigenin (Luc) was undertaken with the flow cells for investigating the effect of the mixing modes on the intensity of light emission. The factors affecting the intensity of light emission were also characterized in terms of the flow rate and CL enhancers.

\section{Experimental}

\section{Materials}

Epinephrine (EP) and periodate sodium were bought from Wako Pure Chemical Industries (Tokyo, Japan). 10,10'Dimethyl-9,9'-biacridinium dinitrate (lucigenin: Luc) and hexadecyltrimethylammonium hydroxide $(\mathrm{CTAOH})$ were obtained from Tokyo Kasei (Tokyo, Japan). An EP solution was prepared daily by dissolving the salts in $1.0 \times 10^{-2} \mathrm{M} \mathrm{HCl}$. The base solutions were prepared from sodium hydroxide. All chemicals used were guaranteed-grade reagents and were used without further purification. All solutions were prepared with ultrapure deionized water from a Millipore Mill-Q waterpurification system.

All of the reagent concentrations reported and shown in the figure captions are the initial solution concentrations.

\section{Fabrication of a micro-flow cell on a silicon chip}

The micro-flow cells were designed as shown in Fig. 1. The channel depth of flow cells 1 and 2 were designed to be 0.45 and $0.38 \mathrm{~mm}$, respectively. Microchannels on a silicon chip were fabricated as follows: a silicon wafer [p-type, (100) surface, $0.625 \mathrm{~mm}$ thick, opticalpolished] was washed 


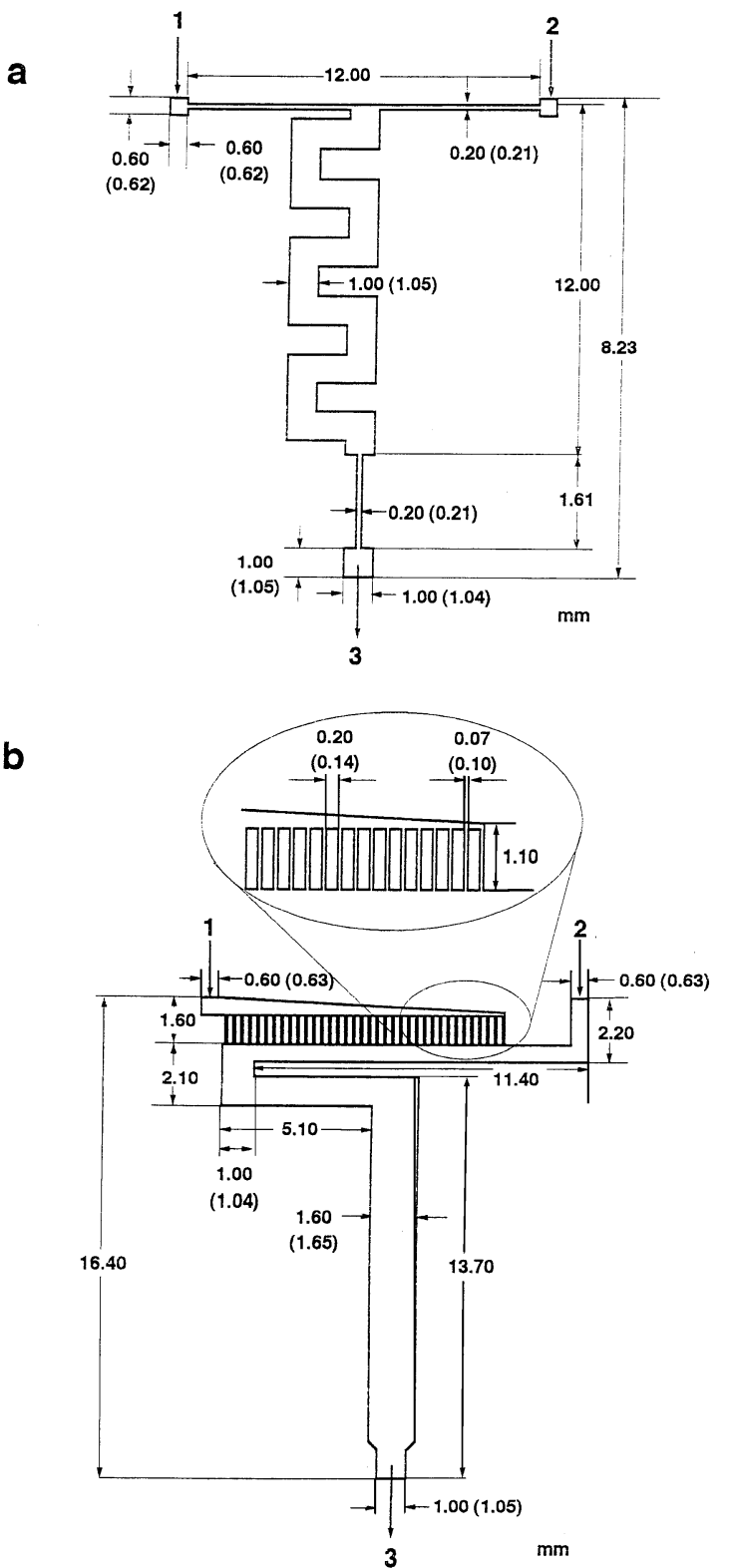

Fig. 1 Micro flow cells. a, flow cell 1; b, flow cell 2. 1, inlet of a Luc solution containing EP; 2, inlet of an alkaline solution; 3, outlet of a mixture solution. The observed values of the channel width are shown in parentheses.

sequentially with a mixture of water, ammonia water, and hydrogen peroxide $(5: 1: 1)$ at $80^{\circ} \mathrm{C}$ for $10 \mathrm{~min}$, and a mixture of water, hydrochloric acid, and hydrogen peroxide $(6: 1: 1)$ at $80^{\circ} \mathrm{C}$ for $10 \mathrm{~min}$. The wafer was thermally oxidized with steam under a nitrogen stream at $1100^{\circ} \mathrm{C}$ for $10 \mathrm{~h}$ with in an oven. The thickness of the oxidized layer at this stage was approximately 2 $\mu \mathrm{m}$. Spin-coating with a positive-type photoresist (OFPR-800, Tokyo Ohka Kogyo, Japan) was carried out by a spin coater (Model 1H-DXII, Mikasa, Japan). After prebaking at $80^{\circ} \mathrm{C}$ for $15 \mathrm{~min}$, the photoresist layer was photolithographically developed with a photomask to make a channel. Postbaking was performed at $130^{\circ} \mathrm{C}$ for $5 \mathrm{~min}$. The oxidized layer was etched in a hydrogen fluoride-buffered solution (hydrogen fluoride: ammonium fluoride $=1: 7$ ). The photoresist was then removed completely by washing with acetone and water. Anisotropic etching was carried out in a mixture of potassium hydroxide, isopropyl alcohol, and water $(100 \mathrm{~g}: 50 \mathrm{ml}: 300 \mathrm{ml})$ at

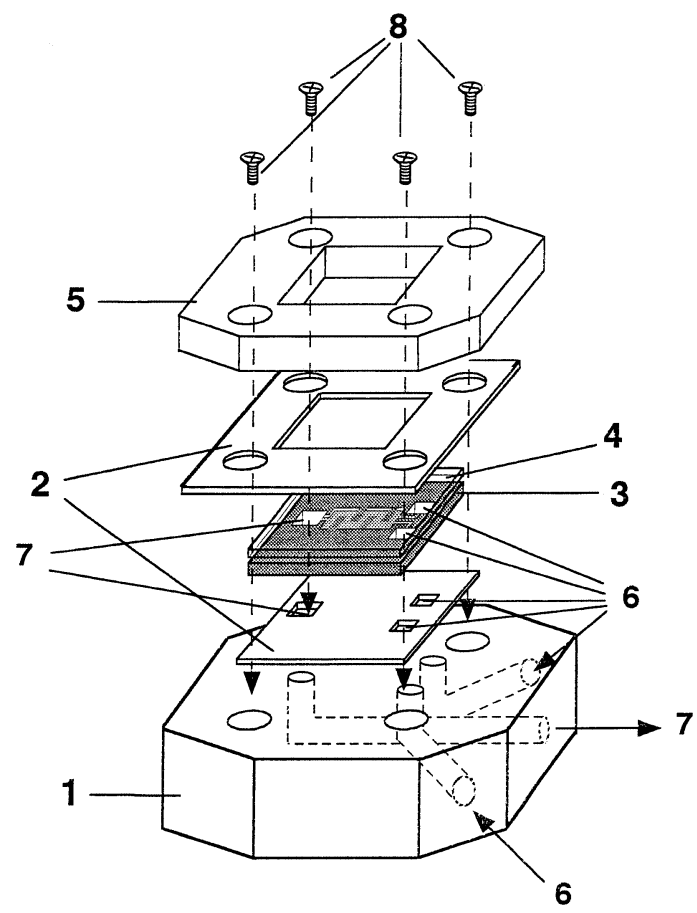

Fig. 2 Structure of a chip-holder. 1, acrylate resin; 2, silicone rubber; 3 , micro flow cell; 4, Pyrex glass; 5, copper plate; 6 , inlet hole; 7 , outlet hole; 8 , stainless-steel screw.

$75^{\circ} \mathrm{C}$ to make a channel on the silicon chip. The (111) planes were produced by anisotropic etching on the (100) surface. The etching angle between the (100) surface and the (111) surface is $54.7^{\circ} .{ }^{11}$ The section of the flow cells of 1 and 2 was trapezoid grooves. The reversed side was also etched in the same manner with a photomask to make holes for the inlet and outlet. Next, the oxidized layer of the wafer was stripped with the buffered solution. Finally, the silicon wafer was anodically bonded to a Pyrex glass plate (Pyrex 7740, Corning). Anodic bonding was carried out at $400^{\circ} \mathrm{C}$ and $600 \mathrm{~V}$ for $3 \mathrm{~h}$.

The width and depth of the channel were measured using a profile micrometer (Model VF-7510, Keyence, Japan) and a surface profiler (Model Surfcom 300B, Tokyo Seimitsu, Japan). The observed values of the channel width are shown in parentheses in Fig. 1. The channel depths of flow cells 1 and 2 were 0.40 and $0.35 \mathrm{~mm}$, respectively. The thus-calculated volumes of flow cells 1 and 2 were about 7 and $10 \mu \mathrm{l}$, respectively.

\section{Flow CL detection system of EP with Luc}

The flow cell consisted of an anisotropically etched silicon chip and a Pyrex glass plate. Each plate was a $25 \mathrm{~mm}$ x $25 \mathrm{~mm}$ square plate. The silicon chip had a channel, and penetrating holes at each end of the channel. The thicknesses of the Pyrex glass, silicone rubber and acrylate resin were $0.3,0.5$ and 15 $\mathrm{mm}$, respectively. The diameter of inlet and outlet holes in acrylate resin was $1.5 \mathrm{~mm}$. The flow cell was fixed on a chipholder, as shown in Fig. 2. The chip-holder was faced to a photomultiplier tube (PMT) in the CL detector.

Figure 3 shows the FIA system for the CL detection of EP with Luc. A Luc solution and an alkaline solution were pumped by an HPLC pump (minimum flow rate $5 \mu \mathrm{l} / \mathrm{min}$, Model PU611, GL Sciences, Tokyo, Japan). Teflon tubing (0.8-mm i.d.) was used for the flow line. A solution containing EP was injected into the Luc carrier stream using a rotary valve 


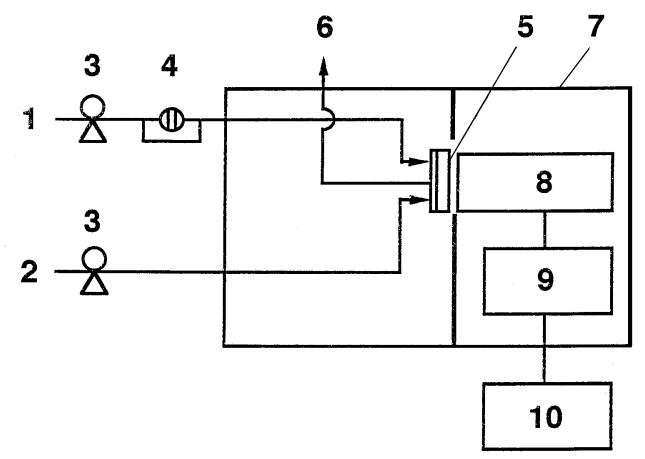

Fig. 3 Flow diagram of the FIA system for CL detection of EP with Luc. 1, a Luc solution; 2, an $\mathrm{NaOH}$ solution; 3, HPLC pump; 4, rotary valve; 5 , micro flow cell; 6 , waste of a mixture solution; $7, \mathrm{CL}$ detector; 8, photomultiplier; 9 , amplifier; 10 , recorder.

(Rheodyne 7120) with a 5- $\mu$ l sample loop. In micro flow cell 2 , the solution containing Luc and EP introduced from the inlet of 1 passed through the nozzles and was injected to the alkaline solution which entered from the inlet of 2 . In order to prevent a pressure drop of the alkaline solution, the channel width of the alkaline solution was spread compared to that of the Luc solution.

Light emission was detected by a PMT in a CL detector (Model ICA-3070, TOA Electronics Ltd., Tokyo, Japan). The resultant photocurrent was converted to a voltage, whose value was displayed on a recorder (Model R-61, Rikadenki Kogyo, Tokyo, Japan). Light emission from the flow cells was imaged by a cooled charge-coupled device (CCD) camera (Model C4880-30-24A, Hamamatsu Photonics, Hamamatsu City, and Japan). The CCD was cooled to $-50^{\circ} \mathrm{C}$ to minimize the dark current. The flow cells were faced to a lens of a CCD camera in a dark box. The flow system for measuring the light emission by a CCD camera was similar to that shown in Fig. 3 .

\section{Results and Discussion}

\section{Measurement of $C L$ response curves}

We previously found that EP reacts with Luc in an aqueous alkaline solution to form EP oxidants and 3-methylacridone with concomitant light emission: ${ }^{12}$

$$
\mathrm{EP}+\mathrm{Luc} \longrightarrow \mathrm{EP} \text { oxidants + 3-methylacridone + light }
$$

Light emission reached its maximum height in $5 \mathrm{~s}$, and then decayed at a much slower rate. The intensity of the maximum light emission was linearly related to the EP concentration. The determination of EP, a group of catecholamines, is primarily useful for the diagnosis for various diseases and an evaluation of their medical treatments. ${ }^{13-15}$ We then proposed the Luc CL method for the determination of EP by a conventional batch method. ${ }^{12}$

Two flow-lines were assembled in the micro FIA system, as shown in Fig. 3, by taking into account the CL reaction of EP with Luc. The EP solution acidified with $\mathrm{HCl}$ was injected into the Luc carrier stream, since the CL reaction of EP with Luc proceeds under an alkaline condition. ${ }^{12}$ Finally, the alkaline solution and the Luc solution containing EP were injected into the flow cell. The final $\mathrm{pH}$ was 11.6 after mixing the two solutions.

The CL measurements were made according to a procedure in



Fig. 4 Typical CL response curves. Conditions for the CL measurements. $[\mathrm{EP}]=1.0 \times 10^{-4} \mathrm{M},[\mathrm{Luc}]=1.0 \times 10^{-4} \mathrm{M},[\mathrm{NaOH}]=$ $0.20 \mathrm{M}$, flow rate $=10 \mu \mathrm{l} / \mathrm{min}$. At the arrow, EP was added.

which a $0.20 \mathrm{M}$ solution of $\mathrm{NaOH}$ and a $1.0 \times 10^{-4} \mathrm{M}$ solution of Luc were successively loaded into the flow cells at a flow rate of $10 \mu \mathrm{l} / \mathrm{min}$. A 5 - $\mu \mathrm{l}$ portion of a $1.0 \times 10^{-4} \mathrm{M}$ solution of EP was injected into the Luc carrier stream. Typical CL response curves are shown in Fig. 4. The light emission reached maximum intensity in $2 \mathrm{~min}$ in both flow cells. No CL was observed upon the injection of a blank solution, which contained no EP. The maximum light emission is referred to as the CL intensity. The CL intensity in flow cell 2 increased by a factor of two times compared to that in flow cell 1.

In flow cell 1, the Luc stream containing EP and the alkaline solution entered the flow cell through separate inlet ports, and the two streams came into contact at the entrance of the flow cell. The reactants, such as Luc, EP and hydroxyl ion in the fluid, can diffuse significant distances between the two streams during the average residence time in the flow cell, thus resulting in the occurrence of the CL reaction. On the other hand, in flow cell 2, the Luc solution containing EP passed through narrow nozzles and was split up into 36 partial flows. Consequently, many smaller segments of the Luc solution containing EP were injected into the alkaline solution. Therefore, the differences in the CL intensity in flow cells 1 and 2 could be explained in terms of the differences in the mixing mode of the reactants. A fluid in a microchannnel is known to flow with laminar flow.? However, the results observed in flow cell 2 indicate that the distortion of laminar flow could occur by passage of the Luc solution through the nozzles, thus resulting in an increase of the CL intensity.

On the other hand, light emission was observed for about a 10-min period in both flows cells, as shown in Fig. 4. The observed time was appreciably longer than the time predicted by the flow rate and total volume of the flow cell and the outlet hole. The volume of the outlet hole in the chip-holder was about $17 \mu \mathrm{l}$. Therefore, the result indicates that it needs a long time for replacing EP in the flow cell and the outlet hole.

\section{Effect of the flow rate on the CL intensity}

The dependence of the CL intensity upon the flow rate was investigated in the range of $5-100 \mu \mathrm{l} / \mathrm{min}$. Figure 5 shows the CL intensity-del. flow rate profiles. The CL intensities exhibited a maximum at $10 \mu \mathrm{l} / \mathrm{min}$ in the flow cell 1 and at 20 $\mu 1 /$ min in flow cell 2 , above which the CL intensities decreased remarkably with an increase in the flow rate. The CL intensities were independent of the flow rate in the range of 50-100 $\mu \mathrm{l} / \mathrm{min}$.

The increase of the CL intensity in the range of $5-20 \mu \mathrm{l} / \mathrm{min}$ 


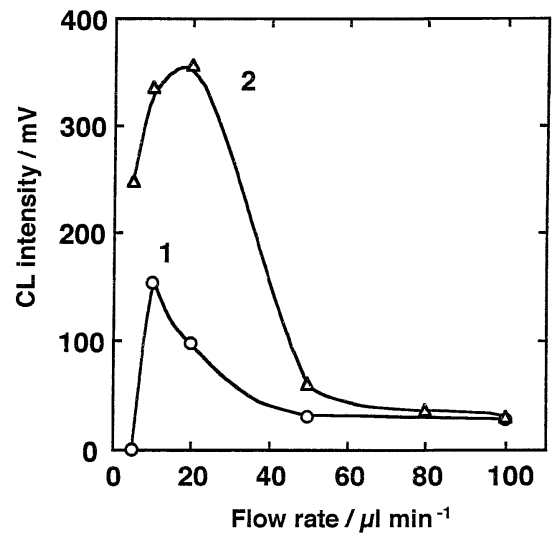

Fig. 5 Effect of the flow rate on the CL intensity. 1, flow cell 1;2, flow cell 2. Conditions for the CL measurements. $[\mathrm{EP}]=1.0 \times 10^{-4}$ $\mathrm{M},[\mathrm{Luc}]=1.0 \times 10^{-4} \mathrm{M},[\mathrm{NaOH}]=0.20 \mathrm{M}$.

could be due to an increase in the diffusion efficiency of the reactants accompanying an increase in the flow rate. On the other hand, the rate-determining step for light emission could be supposed to be the step of the CL reaction, since light emission was observed for a few minutes in the batch method. ${ }^{12}$ Therefore, the decrease of the CL intensity above $10 \mu \mathrm{l} / \mathrm{min}$ in flow cell 1 and $20 \mu \mathrm{l} / \mathrm{min}$ in flow cell 2 can probably be attributable to a decrease in the residence time of the reactants, since the increase in the flow rate could be responsible for the decrease in the residence time of the reactants. At the flow rates of $50-100 \mu \mathrm{l} / \mathrm{min}$, the decrease in the residence time and the increase in the mixing efficiency of the reactants could compensate each other, thus resulting in a constant value of the CL intensity.

\section{Effects of CL enhancers on the CL intensity}

In order to increase the CL intensity, CL enhancers were applied to CL detection in the micro FIA system. Periodate ${ }^{16}$ and cationic micellar $\mathrm{CTAOH}^{17}$ acted as an enhancer in the LucCL detection of EP in the batch method. The CL enhancement in the presence of periodate or cationic micellar $\mathrm{CTAOH}$ was explained in terms of an increase in the oxidation rate of EP to EP quinone, which is responsible for the Luc-CL reaction. ${ }^{18}$

First, the CL intensity was measured by adding periodate into the alkaline solution. The CL intensity-periodate concentration profiles in flow cells 1 and 2 are shown in Fig. 6 . The CL intensity increased remarkably in flow cell 2 compared to that in flow cell 1. This result indicates that the oxidation of EP by periodate could proceed more effectively in flow cell 2 . The decrease of the CL intensity above $1.0 \times 10^{-3} \mathrm{M} \mathrm{NaIO}_{4}$ is probably attributable to the decrease in the concentration of EP quinone, because the oxidation of EP will be accelerated with an increase in the $\mathrm{NaIO}_{4}$ concentration. ${ }^{18}$

Next, we added an aqueous CTAOH solution into both the Luc solution and the alkaline solution. Figure 7 shows the CL intensity-CTAOH concentration profiles. No CL enhancement in the presence of $\mathrm{CTAOH}$ was observed in both flow cells 1 and 2. The formation of micellar $\mathrm{CTAOH}$ was important in the CL enhancement in the batch method. However, no CL enhancement was observed above the critical micelle concentration, which was $9 \times 10^{-4} \mathrm{M}$ for $\mathrm{CTAOH} .{ }^{19}$ In flow cell 1 , the CL intensity decreased above $5.0 \times 10^{-4} \mathrm{M} \mathrm{CTAOH}$. These results could be explained by taking into account the effect of cationic surfactants on the flow. Cationic surfactants are known to be effective as a drag reducer. ${ }^{20}$ Therefore, the

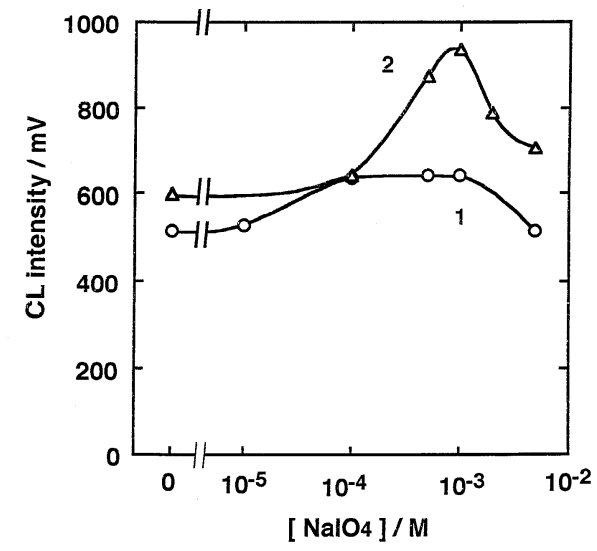

Fig. 6 Effect of the periodate concentration on the CL intensity. 1, flow cell $1 ; 2$, flow cell 2 . Conditions for the CL measurements of flow cell 1: $[\mathrm{EP}]=5.0 \times 10^{-5} \mathrm{M},[\mathrm{Luc}]=5.0 \times 10^{-4} \mathrm{M},[\mathrm{NaOH}]=$ $0.20 \mathrm{M}$, flow rate $=10 \mu \mathrm{l} / \mathrm{min}$; and flow cell 2 : $[\mathrm{EP}]=1.0 \times 10^{-4} \mathrm{M}$, $[\mathrm{Luc}]=2.0 \times 10^{-4} \mathrm{M},[\mathrm{NaOH}]=0.20 \mathrm{M}$, flow rate $=20 \mu \mathrm{l} / \mathrm{min}$.

diffusion efficiency could be reduced in the presence of $\mathrm{CTAOH}$, thus resulting in a decrease in the CL intensity. On the other hand, the noise level in the blank solution, which contained no EP, decreased remarkably in the presence of $\mathrm{CTAOH}$. We then added a $5.0 \times 10^{-4} \mathrm{M}$ solution of CTAOH into the Luc solution and the alkaline solution.

\section{Analytical results and parameters}

The calibration curves for EP in the presence of periodate and $\mathrm{CTAOH}$ were prepared under the optimum conditions. The logarithmic calibration curve was linear over the range from the detection limit of $5.0 \times 10^{-6}$ up to $1.0 \times 10^{-4} \mathrm{M}$ with a slope of 1.30 and a correlation coefficient $\left(R^{2}\right)$ of 0.995 upon the use of flow cell 1. The detection limit for EP was defined as the concentration of EP yielding an analytical signal equal to threetimes the standard deviation of the blank CL intensity. On the other hand, upon the use of flow cell 2, the logarithmic calibration curve was linear over the range from the detection limit of $8.0 \times 10^{-7}$ up to $1.0 \times 10^{-4} \mathrm{M}$ with a slope of 1.58 and a correlation coefficient $\left(R^{2}\right)$ of 0.994 . The relative standard deviation of five successive experiments was $3.5 \%$ at $1.0 \times 10^{-5}$ $\mathrm{M}$ of EP. The sensitivity for EP in flow cell 2 was improved by a factor of six times compared to that in flow cell 1 . The sensitivity for EP in the micro FIA system can be applicable to the determination of EP in urine.

\section{Imaging of light emitted from the flow cells}

Light emission from the flow cells was imaged with a CCD camera. Figure 8 shows the image produced by a 10-min exposure of the flow cell to the CCD camera from the start of light emission. The sites in which light emission was observed are shown in white in Fig. 8. In flow cell 1, light emission was observed faintly in the neighborhood of the entrance of the flow cell. In flow cell 2 , light emission appeared intensively around the outlet of the nozzles. The reverse flow of the alkaline solution into the nozzles was observed at the right side of the nozzles. This is probably attributable to an increase in the pressure drop of the Luc solution containing EP at the right side of the nozzles. The intensity of light emission reached maximum around the middle of the flow cell in both flow cells 1 and 2. In addition, light emission was apparently observed at the outlet holes. We then calculated the fraction of light emission from the outlet hole to the total light emission using 


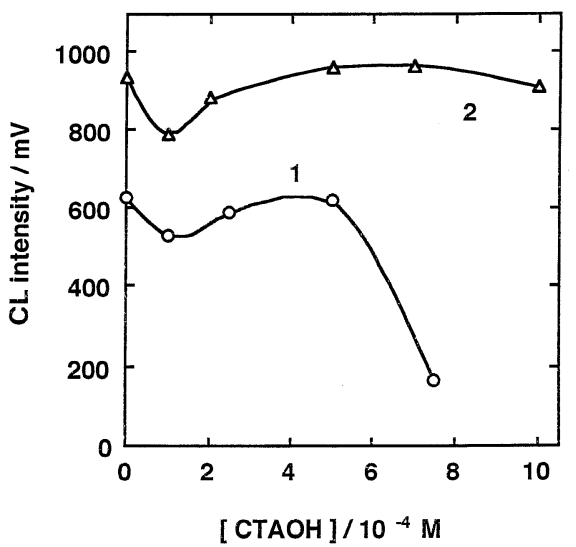

Fig. 7 Effect of the CTAOH concentration on the CL intensity. 1, flow cell $1 ; 2$, flow cell 2 . Conditions for the CL measurements of flow cell 1: $[\mathrm{EP}]=5.0 \times 10^{-5} \mathrm{M},[\mathrm{Luc}]=5.0 \times 10^{-4} \mathrm{M},[\mathrm{NaOH}]=$ $0.20 \mathrm{M}$, flow rate $=10 \mu \mathrm{l} / \mathrm{min}$; and flow cell $2:[\mathrm{EP}]=1.0 \times 10^{-4} \mathrm{M}$, $[\mathrm{Luc}]=2.0 \times 10^{-4} \mathrm{M},[\mathrm{NaOH}]=0.20 \mathrm{M}$, flow rate $=20 \mu \mathrm{l} / \mathrm{min}$.

the data obtained by the CCD camera. The fraction of light emission from the outlet hole was $12 \%$ and $5 \%$ in flow cells 1 and 2 , respectively. These results suggest that the difference in the CL intensity in flow cells 1 and 2, as shown in Fig. 4, could be due to the differences in the light emission from the flow cells. Therefore, the efficiency of the CL reaction in the flow cell could be influenced by the mixing mode at the inlet of the flow cell.

In conclusion, the efficiency for the CL reaction of EP in the micro flow cell was dependent on the mixing mode of the entrance in the flow cell. The resolution of the Luc solution containing EP to many smaller segments by passage through the nozzles was effective for enhancing the CL intensity. Periodate acted as an enhancer in the CL reaction of EP with Luc in the microfluid. However, cationic micellar CTAOH was not effective for CL enhancement. Therefore, an investigation of mixing devices and CL enhancers in the microfluid could be important for the improving the sensitivity in the CL method.

\section{Acknowledgements}

This work was supported by a Grant-in-Aid for Scientific Research (B) from the Ministry of Education, Culture, Sports, Science and Technology (No. 11450319).

\section{References}

1. J. Ruzicka and E. H. Hansen, "Flow Injection Analysis", 2nd ed., 1988, Wiley, New York.

2. K. Sato, M. Tokeshi, T. Kitamori, and T. Sawada, Anal. Sci., 1999, 15, 641 .

3. P. S. Hodder, G. Blankenstein, and J. Ruzicka, Analyst [London], 1997, 122, 883.

4. S. D. Mangru and D. J. Harrison, Electrophoresis, 1998, 19,2301

5. M. Hashimoto, K. Tsukagoshi, R. Nakajima, K. Kondo, and A. Arai, J. Chromatogr. A, 2000, 867, 271

6. X.-Z. Wu, M. Suzuki, T. Sawada, and T. Kitamori, Anal. Sci., 2000, 16, 321

7. A. E. Kamholz, B. H. Weigl, B. A. Finlayson, and P.


Fig. 8 CCD camera imaging of light emission from the flow cells. a, flow cell $1 ; \mathrm{b}$, flow cell 2 . Conditions for the CL measurements of flow cell 1: $[\mathrm{EP}]=1.0 \times 10^{-4} \mathrm{M},[\mathrm{Luc}]=5.0 \times 10^{-4} \mathrm{M},[\mathrm{NaOH}]=$ $0.20 \mathrm{M},\left[\mathrm{IO}_{4}^{-}\right]=5.0 \times 10^{-4} \mathrm{M},[\mathrm{CTAOH}]=5.0 \times 10^{-4} \mathrm{M}$, flow rate $=$ $10 \mu \mathrm{l} / \mathrm{min}$; and flow cell $2:[\mathrm{EP}]=1.0 \times 10^{-4} \mathrm{M},[\mathrm{Luc}]=2.0 \times 10^{-4} \mathrm{M}$, $[\mathrm{NaOH}]=0.20 \mathrm{M},\left[\mathrm{IO}_{4}^{-}\right]=5.0 \times 10^{-4} \mathrm{M},[\mathrm{CTAOH}]=5.0 \times 10^{-4} \mathrm{M}$, flow rate $=20 \mu \mathrm{l} / \mathrm{min}$.

Yager, Anal. Chem., 1999, 71, 5340.

8. M. Elwenspoek, T. S. J. Lammerink, R. Miyake, and J. H. J. Fluitman, J. Micromech. Microeng., 1994, 4, 227.

9. F. G. Bessoth, A. J. deMello, and A. Manz, Anal. Commun., 1999, 36, 213.

10. Y. Xu, F. G. Bessoth, J. C. T. Eijkel, and A. Manz, Analyst, 2000, 125, 667.

11. K. E. Petersen, "Microsensors", ed. R. S. Muller, R. T. Howe, S. D. Senturia, R. L. Smith, and R. M. White, 1990, Section 2.1, IEEE Press, New York, 38.

12. T. Kamidate, K. Yoshida, T. Segawa, and H. Watanabe, Anal. Sci., 1989, 5, 359.

13. R. Nozaki, H. Kawamoto, and H. Moriyama, Luminescence, 1999, 14, 369.

14. R. Zhu and W. T. Kok, Anal. Chem., 1997, 69, 4010

15. H. Arakawa, M. Kanemistu, and M. Maeda, Anal. Sci., 1999, 15, 1269.

16. T. Kamidate, T. Kaneyasu, T. Segawa, and H. Watanabe, Chem. Lett., 1991, 1719.

17. T. Kamidate, T. Yoshida, T. Kaneyasu, T. Segawa, and H. Watanabe, Anal. Sci., 1990, 6, 645.

18. T. Kamidate, H. Ichihashi, T. Segawa, and H. Watanabe, $J$. Biolumin. Chemilumin., 1995, 10, 55.

19. W. L. Hinze, T. E. Riehl, H. N. Singh, and Y. Baba, Anal. Chem., 1984, 56, 2180.

20. B. Lu, X. Li, L. E.Scriven, H. T. Davis, Y. Talmon, and J. L. Zakin, Langmuir, 1998, 14, 8. 